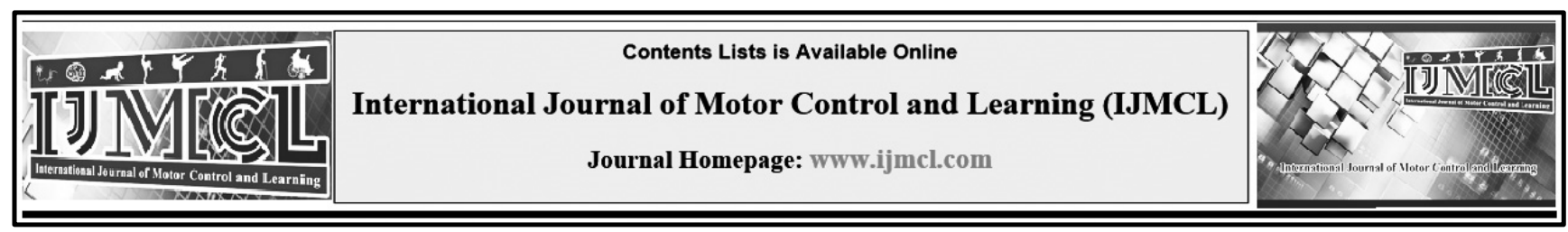

\title{
Psychometric Analysis of Persian Version of Movement Imagery Questionnaire-Children Form (MIQ-C)
}

\author{
Meysam Yavari Kateb ${ }^{a}$, Hassan Gharayagh Zandi ${ }^{b *}$, Ali Moghadam Zadeh ${ }^{c}$ \\ ${ }^{a}$ Master's Degree in Sport Psychology, College of Sport Sciences, Tehran University, Tehran, Iran \\ ${ }^{\mathrm{b}}$ Assistant Professor, Faculty of Sport Sciences, University of Tehran, Tehran, Iran \\ ${ }^{\mathrm{c} A s s i s t a n t}$ Professor, Faculty of Psychology and Educational Sciences, Tehran University, Tehran, Iran
}

\begin{tabular}{|c|c|}
\hline Keywords & Abstract \\
\hline Down syndrome & Background: Previous studies have shown that Movement Imagery ability is \\
\hline Functional strength training & $\begin{array}{l}\text { effective in learning and motor function in the sport as well as in rehabilitation. So, } \\
\text { self-reporting questionnaires have been developed to evaluate the ability of Movement }\end{array}$ \\
\hline Gait kinematics & Imagery in adults (e.g. MIQ-3) to be validated in Iran. There is currently no proper \\
\hline & tool to use for children in Iran. \\
\hline Isokinetic peak torque & Objective: To fill this gap, the focus of this study was to examine the functional \\
\hline Static balance & $\begin{array}{l}\text { structure of the Children's Movement Imagery Questionnaire. } \\
\text { Methods: The statistical population included children from } 7 \text { to } 12 \text { years old (135 } \\
\text { boys, } 109 \text { girls) who were selected by random cluster sampling. At first, the } \\
\text { questionnaire was translated into Persian. After necessary corrections, both } \\
\text { exploratory factor analysis (EFA) and confirmatory factor analysis (CFA) were used }\end{array}$ \\
\hline Hassan Gharayagh Zandi, & to examine the factor structure. \\
\hline Email: ghzandi110@ut.ac.ir & $\begin{array}{l}\text { Results: Exploratory factor analysis showed that the present log consists of three } \\
\text { folded scales and } 12 \text { materials that ultimately were tested and validated the three- } \\
\text { factor model through the confirmatory factor analysis. Also, the total reliability for the }\end{array}$ \\
\hline Received: 2019/05/19 & factors was calculated by Cronbach's alpha method and equaled with 0.845 , which \\
\hline Accepted: $2019 / 07 / 28$ & indicates the reliability of the mentioned logic. \\
\hline Published: 2019/08/19 & $\begin{array}{l}\text { Conclusions: The Persian version of the current questionnaire is recommended to } \\
\text { measure the children Imagery ability, from } 7 \text { to } 12 \text { years of age in the Persian } \\
\text { language. }\end{array}$ \\
\hline
\end{tabular}

\section{Introduction}

Today, sport and exercise psychology have significantly changed the lives of athletes, coaches, and other sports practitioners (Weinberg \& Gould, 2011). With the advancement of sports psychology, mental skills play an important role in the performance of sporting activities, in which the performance and sports performance of individuals are largely influenced by psychological factors.
While already emphasizing the importance of physical fitness, today's prominent athletes emphasize psychological preparation more than before (Halavari \& Thomassen, 1997; Azadi, 2011). For many years, athletes have been practicing or reviewing their motor skills mentally. In fact, many types of research, titled "Mental Exercise" (to distinguish it from physical exercise), 
have been investigated in different situations (Richardson, 1967; Jackson, Lafleur, Malouin, Richards \& Doyon, 2001; Saab, Bastek, Dayaratna, Hutton \& Catherine, 2017). Athletes and coaches use various functional methods such as relaxation, imagery, goal-setting, self-talk, biofeedback, behavior management and function profile in the process of mental training (Smith, Wright \& Cantwell, 2008). Among different ways of mental training, imagery is of particular importance and is more relevant to athletes, coaches and sports psychologists (Cumming \& Williams, 2013). It is referred to as "central pillar of applied sports psychology" (Mattie \& Chandler, 2012). The ability to imagine doing activity in the mind, such as creating a mental image, is an important factor for the learning, development, and performance of the motor task (Hemayat Talab, Sheykh, Movahed \& Asad, 2007; Guillot \& Collet, 2008; Schuster \& et al., 2012). Mental imagery is increasingly being used as an interventional strategy to improve athletic performance as well as to improve the motor task performance at rehabilitation (Cumming \& Williams, 2012). According to the coaches' view, mental imagery is the most useful psychic skill that an executor can use, more than any other way, to improve performance (Knackstedt, 2011). It is assumed that mental imagery of activity provides how to imagine an action in mind in order to plan for effective action (Skoura, Vinter \& Papaxanthis, 2005; Gabbard \& Bobbio, 2011. In addition, the same nervous mechanisms that participate in learning with physical exercise, are also active in mental training (Hemayat Talab \& et.al, 2007).

In fact, training with mental imagery can create a common nervous system like exercise (Heremans, Helsen \& Feys, 2012). Also, according to researchers, the use of mental imagery to simulate movements by practicing areas of the brain that are shared between physical exercise and imagery can facilitate performance and also accelerate learning (Cumming \& Williams, 2013). Performing mental activity without physical movement (Jeannerod, 1995), a complex and multidimensional structure (White \& Hardy, 1995; Hall \& Martin, 1997). Vealey and Greenleaf(2001) define imagery as the use of all senses in order to create or recreate an experience in the absence of external stimuli. The components of motor imagery are how the person "senses" the movement, which includes awareness of the position and movement of different parts of the body, such as the force and the effort that is felt during the movement. The visual component refers to the representation of what one sees (such as space, size, and scope) (Callow \& Waters, 2005). The mental imagery of activity can include various perspectives including internal perspective (first person) and external view (third person) (White \& Hardy, 1995). When one imagines a move as it really is, it refers to the use of the internal perspective (Jeannerod, 1995; McAvinue \& Robertson, 2008) and the external viewpoints out that it looks like someone is moving on to watch TV or video. Recent studies show that the imagined movement from both the first and third person views may include the same 
representation (Jeannerod, 1995). Everyone can use motor imagery, although some do it better. Guillot and Colette (2008) stated that there is a strong correlation between motor imagery and performance and motor learning capabilities. Research shows that imagery ability can be improved by training to improve motor function and learn skills (McAvinue \& Robertson, 2009). Similarly, improving motor imagery ability may be useful for people with motorized problems, such as children with coordination problems (Gabbard, Caçola \& Bobbio, 2011). In order to be able to assess whether the ability to motor imagery can have such benefits, we need to have a standard measurement tool that measures this ability. Although there are several types of these tools for adults, there are still no standard tools for the use of Persian-speaking Iranian children. Previous studies have shown that children, like adults, have the ability to create and use imagery. Most Imagery studies have been conducted among adults (Gabbard, 2009) but some studies suggest that mental imagery can be useful for younger athletes as well as adults (Molina, Tijus \& Jouen 2008; Wakefield \& Smith 2009; Munroe-Chandler, Hall \& Fishburne, 2012). Apparently, younger athletes, as well as older ones, can use mental imagery anywhere (before, during and after the competition and at free time, such as before bedtime). In addition, it has been shown that from a functional point of view, athletes aged 7-14 use some kind of imagery (Veraksa \& Gorovaya 2009). The results also showed that movement imagery is suitable for children aged 7 years and older (Spruijt, Kamp \&
Steenbergen, 2015). In fact, the ability to use movement imagery between the ages of 7 and 12 grows (Caeyenberghs, Tsoupas, Wilson \& Smitsengelsman, 2009) and it seems that these changes coincide with the development of the necessary cognitive processes that represent the movement and the planning and implementation of the action (Molina \& et al., 2008). The use of adult questionnaires for children also reports inconsistent results (Isaac \& Marks, 1994; Taktek, 2008) and, in general, the use of an adult questionnaire in children is problematic since children may not understand all the words and concepts and can't properly understand what the questionnaire wants from them (Stadulis 2002). Skills imagination training is very effective in increasing motor capability (Rogers, Hall \& Buckholz, 2003) and the usefulness of mental training also depends on the individuals' imagery ability (Isaac \& et al., 1994; Mantani \& et al., 2005). Therefore, a proper tool is necessary. Although there are several movement imagery questionnaires, their factor structure in Iran has been studied only for adults, and there are no movement imagery questionnaires for children in Iran. Considering the potential changes in children's imagery capability, the first important step in understanding its effects on children's motor performance and learning is the proper tool for measuring children's imagery capability.

The questionnaire used in the present study is the Movement Imagery Questionnaire for Children, developed and validated by Martini and et al. in 2016. The results showed that this 
questionnaire has a very good structure Comparative Fit Indices (CFI) of 0.93, TuckerLewis fit index (TLI) of 0.89 and Root Mean Square Error of Approximation (RMSEA) estimation and finally concurrent narrative for the subscales of this questionnaire. The present questionnaire was taken from the MIQ Motor Imagery Questionnaire and its latest version, the Movement imagery-3 Questionnaire (MIQ-3) (Williams \& et al., 2012). Where three subscales, including internal visual imagery, external visual imagery, and kinesthetic imagery, are measured. In the present version, adopted by the MIQ-3, they have adopted a special approach to measure the imagery of other questionnaires, so that in the current version, participant make a physical move before creating the image in their minds (Martini \& et al., 2016). In addition, the researchers provided a specific guide for how to imagery or execute motion. Cagliari (2008) notes that without such an instruction, there is no particular change in the minds of individuals. Providing such an instruction will allow the researcher to make sure participant understand the move well before performing the imagery. Considering the above-mentioned factors, the first step in the development of pediatric imagery studies is the proper tool for measuring this ability. Therefore, in this research, the researcher is seeking psychometric analysis of Persian version of movement imagery questionnaire for children (MIQ-C).

\section{Method}

\section{Participants}

Considering that the required sample in the exploratory factor analysis of the 20-item questionnaires is 15 to 20 participants per item proposed (Kline, 2011), and given that the number of items in this scale is 12,244 children were selected by random cluster sampling (\%44 girl, $\% 56$ boy). For each question, an average of 20.88 people with a mean age of 9.48 was selected as the statistical sample.

\section{Measure}

Movement Imagery Questionnaire for Children (MIQ-C) data collection consisted of demographic questions that included two open-ended questions (name and age) and a closed-ended question (gender). The main part was the children's form of movement imagery questionnaire in general. This questionnaire consisted of 12 questions and four types of moves, three of which are internal visual imagery (Scripts: 2-5-8-11), external visual imagery (Scripts: 3-6-9-12) and kinesthetic imagery (Values: 1-4-7-10) and each scale has four questions and the scoring is based on the Likert scale of 7 values in a range (very difficult to very easy) (Martini \& et al., 2016).

\section{Procedure}

Most participants completed the MIQ-C in pen and paper form. Having provided their informed consent, participants were asked to read the instructions at the top of the form and to answer all questions. Questionnaires were completed in the 
classroom of students in schools, and if required, additional descriptions were provided by the examiner. Typically, after completing the measure, participants were debriefed and thanked for their time.

\section{Data analysis}

Descriptive statistics was used to calculate central indicators and dispersion and drawing tables. Subsequently, to find out the assumptions of using factor analysis, Kaiser-Meyer-Olkin (KMO) tests and the Bartlett Spread Test were used. Then, the exploratory factor analysis, using Maximum Likelihood Method and Direct Oblimin rotation (Costello \& Osborne, 2005), were used to determine the number of factors and Confirmatory Factor Analysis for fitting the obtained factors. Statistical operations were conducted using SPSS (21) and LISREL (8.71).

\section{Results}

Based on the findings of the present study, the KMO index was 0.839 ; therefore, this questionnaire could be reduced to a number of underlying and fundamental factors. In addition, the Bartlett sprite test $\left(\chi^{2}=1133 / 478\right.$, df $=66$, $\mathrm{P}<0 / 001)$ showed that the correlation between the units is not a single matrix; therefore, no correlation was observed between the items of an agent and other factors (Bartlet, 1950; Marcel \& Paquet, 2005). These findings indicate the assumptions needed to use exploratory factor analysis in this study.

\section{Exploratory Factor Analysis of Motor Imagery Questionnaire-Children form}

To verify the factor structure of the questionnaire, the Maximum Likelihood Method was used. In order to determine the number of components, Eigenvalue was plotted and based on the Scree Plot, the number of factors to be extracted was determined. Also, the ratio of variance explained by each factor was determined. Finally, in order to obtain a meaningful structure from factor loads, due to the correlation of the factors, the components extracted on the basis of the rotation were propagated by the direct Oblimin method. Regarding the fact that there are disagreements among the experts about the significance level of the factor definition of factors, in order to investigate the nature of the relationships between variables and also to achieve the definitions of factors, the coefficients of this study are higher than 0.33 in Definition of factors was considered as a rule and coefficients less than these limits were considered as zero (random factor) (Tabachnik, 2006). 


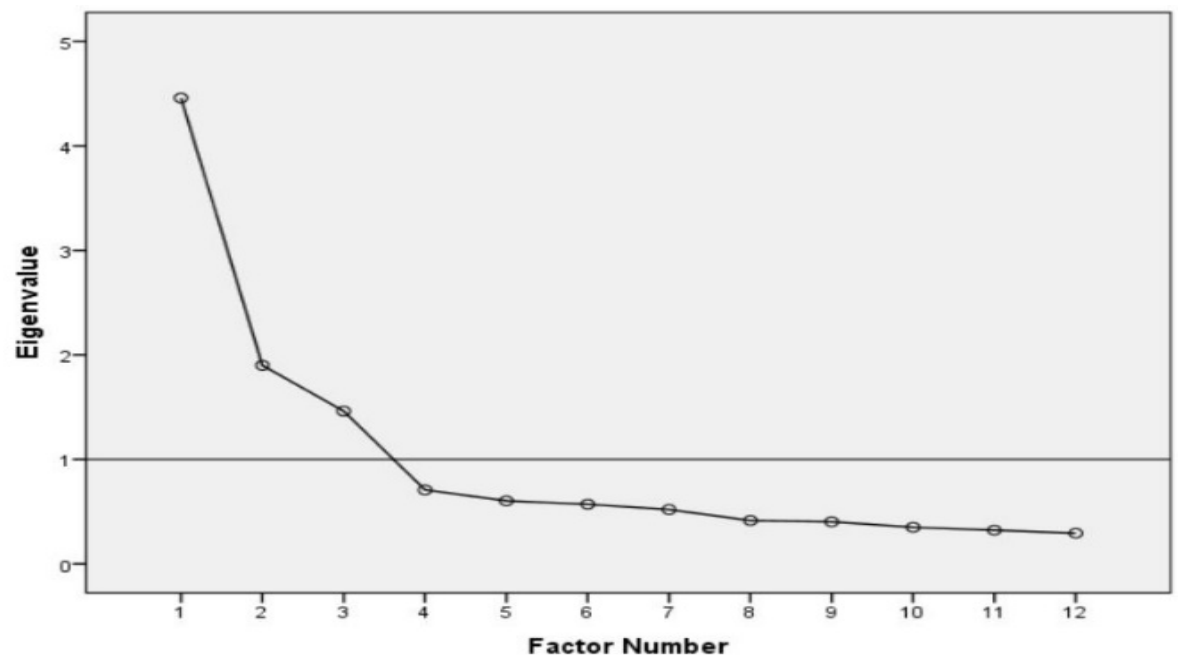

Fig 1. Scree Plot.

Table 1. Matrix Pattern based on the Direct Oblimin Rotation Method.

\begin{tabular}{|c|c|c|c|c|}
\hline & Item & Factor 1 & Factor 2 & Factor 3 \\
\hline Question 2, Jump in the air and Land with your feet & & 0.688 & & \\
\hline Question 5, Lift your right knee, Bring it back down & & 0.752 & & \\
\hline Question 8 , Try to touch your toes with your fingertips & & 0.805 & & \\
\hline Question 11, Keep your arm stretched out & & 0.661 & & \\
\hline Question 3, Keep your arm stretched out & & & 0.666 & \\
\hline Question 6, Jump in the air and Land with your feet & & & 0.657 & \\
\hline Question 9, Lift your right knee, Bring it back down & & & 0.815 & \\
\hline Question 12 , Try to touch your toes with your fingertips & & & 0.638 & \\
\hline Question 1, Keep your arm stretched out & & & & 0.717 \\
\hline Question 4, Try to touch your toes with your fingertips & & & & 0.755 \\
\hline Question 7, Keep your arm stretched out & & & & 0.761 \\
\hline Question 10, Jump in the air and Land with your feet & & & & 0.645 \\
\hline
\end{tabular}

Table 2. Total Variance Explained of MIQ-C by Maximum Likelihood Method.

\begin{tabular}{ccccccc} 
Factors & \multicolumn{3}{c}{ Initial Eigenvalues } & & \multicolumn{2}{c}{ Extraction Sums of Squared Loadings } \\
& & & & & & \\
\hline & Total & \% of Variance & Cumulative $\%$ & Total & \% of Variance & Cumulative \% \\
1 & 4.459 & 37.155 & 37.155 & 3.023 & 33.442 & 33.442 \\
2 & 1.900 & 15.833 & 52.988 & 2.586 & 11.814 & 45.256 \\
3 & 1.461 & 12.178 & 65.166 & 3.051 & 8.553 & 53.810 \\
\hline
\end{tabular}

The results of factor matrix explained are shown in Table 1. Scree Plot also suggested three factors (Fig. 1). The results in the totalized explanatory variance table for the Eigenvalue also showed three specially significant higher values than one, with the special values of these factors before the rotation, respectively: first factor (Internal visual imagery): $4 / 459$ that relates to questions 2, 5, 8 and 11; the second factor (External visual imagery): 1,900 which relates to 
questions 3, 6, 9 and 12; and the third factor (kinesthetic imagery): 1/461, which relates to questions 1, 4, 7 and 10, while after the rotation Eigenvalue of the first factor (Internal visual imagery): 3.023 whit $33.442 \%$ of Variance, the second factor (External visual imagery): 2.586 whit $11.814 \%$ of Variance, and the third factor (kinesthetic imagery): 3.051 with 8.553 $\%$ of Variance, which is these values after Rotation is more uniformly distributed among distributed.

factors, and agents account for $\% 53.810$ of the total variance of the test variables (Table 2). In sum, these results showed that the translated scale questions were loaded on their own factors and, like the main scale, retained their three-factor structure.

\section{Confirmatory Factor Analysis}

The results obtained in exploratory factor analysis depend on the instance in which the analysis is carried out and it needs to make mental decisions. For this reason, if the factor structure is validated by a confirmatory factor analysis, the results will be more reliable (Jorekog \& Sorbom, 1996). In this section, considering the theoretical foundations, the history of past studies and the results of exploratory factor analysis, we examined a probabilistic model based on Goodness of Fiting Index. Among structural equilibrium specialists, a general agreement exists on which of the fitness indicators is better estimates of the model does not exist, so a combination of several indicators was reported (Guillot \& Collet, 2008). Selected indicators include: 1$\chi 2 / d f$, which is less than three signs of fitness (Giles, 2002). 2- Goodness of Fit Index (GFI) and Adjusted Goodness of Fit Index (AGFI), their range varies from zero to one, and the closer they are to one, the better the fit of the model with the observed data (Jorekog \& Sorbom, 2004). 3- Root Mean of Residuals (RMR) which values are less than 0.05 very high and between 0.05 and 0.08 is suitable for a suitable model (Giles, 2002). 4- Root Mean Square Error of Approximation (RMSEA): The value of this index is also good for models 0.05 and less, and a model in which this index is 10 or more is poorly matched $(\mathrm{Hu} \&$ Bentler, 1999). 5- Tucker Lewis Index or Non-normed Fit Index (NNFI), Comparative Fit Index (CFI), Incremental Fit Index (IFI) and Bentler-Bonett Index or Normed Fit Index (NFI), the range of these four indices is between zero and one, values higher than 0.85 indicate relative fit and values above $90 \%$ indicating good fitness and higher than 0.95 indicate excellent fitness $(\mathrm{Hu}$ $\&$ et al., 1999). The model was modeled in accordance with the main model of the test key, namely, three factors, in which all four questions fall into one of the factors. As shown in Table 3, the GFI, AGFI, NNFI, CFI, IFI, NFI indices are above 0.9 and the RMSEA $=0.057$, which is less than 0.08 , indicating that the indicators of fitness and Consequently, the fitting fit is a verifiable factor analysis model, 
and also the $\mathrm{RMR}=0.058$, which indicates that the model.

The confirmatory factor analysis values of fit indices of MIQ-C error is negligible. As it is seen, according to the obtained indicators, the proposed model is fit for the previous studies and exploratory factor analysis and is accepted as the final model. The observation of the parameters and the value of $\mathrm{T}$ on the relationship between the questions with the relevant subscales show that the values of $\mathrm{T}$ and factor load are satisfactory. The value of $\mathrm{T}$ in all questions is higher than 2 , which indicates that there is a meaningful relationship between questions and factors in such a way that all observed variables can predict their own factors. A closer examination of the parameter values of each of the questions regarding the factors indicates that in the internal imagery factor, Question 2 (factor load 0.76 and $\mathrm{T}=$ 9.35), in the external imagery factor, Question 3 (Factor load is 0.65 and $\mathrm{T}=8.80$ ), and in the motor imagery factor, question 7 (factor load 0.76 and $\mathrm{T}=8.06$ ) are the most important predictor variables in their own factors and more weight.

\section{The Reliability of the MIQ-C}

In order to estimate the reliability of the scale, the internal consistency calculation method (Cronbach's alpha method) was used. The result of the calculations performed to estimate the reliability of scale factors showed that the number of alpha coefficients for internal imagery subsystems, external imagery, and motor imagery were respectively $0.75,0.84$ and 0.81 , so the reliability of this scale is verified.

\section{Discussion}

Considering the importance of psychological skills and especially imagery in the field of sport psychology and measuring this skill, as well as the importance of talent identification and education at the age of the base, and also the lack of knowledge about the validity and reliability of this questionnaire in Iran, it seems that doing research in this domain can be a reliable, comprehensive and effective tool for dean psychologists of Iran and can make it easier for them to measure this psychological skill in children. One of the most urgent issues is the development of the field of sports psychology at universities. The use of this discipline in sporting environments, of course, the development of psychological techniques in sports, one of the most used of which is illustrated, will surely require the existence of a valid instrument for measuring people's image capability is felt more and more. In addition, there has been a lot of research in the field of mental imagery in Iran that the research was conducted on people who were different in terms of mental imagery, so that subjects were chosen from the beginning as homogeneous, as a tool for their homogeneity did not exist in terms of imaging ability. An investigation into the existence and validation of a tool can greatly overcome such problems. 
Table 3

\begin{tabular}{lc}
\hline Fit index & Observed values \\
\hline$\chi^{2}$ & 91.72 \\
$\mathrm{P}$ & 0.000 \\
$\mathrm{df}$ & 51 \\
$\chi 2 / \mathrm{df}$ & 1.79 \\
Goodness of Fit Index (GFI) & 0.94 \\
Adjusted Goodness of Fit Index (AGFI) & 0.91 \\
Root Mean of Residuals (RMR) & 0.058 \\
Root Mean Square Error of Approximation (RMSEA) & 0.057 \\
Tucker Lewis Index or Non-normed Fit Index (NNFI) & 0.97 \\
Comparative Fit Index (CFI) & 0.98 \\
Incremental Fit Index (IFI) & 0.98 \\
Bentler-Bonett Index or Normed Fit Index (NFI) & 0.95 \\
\hline
\end{tabular}

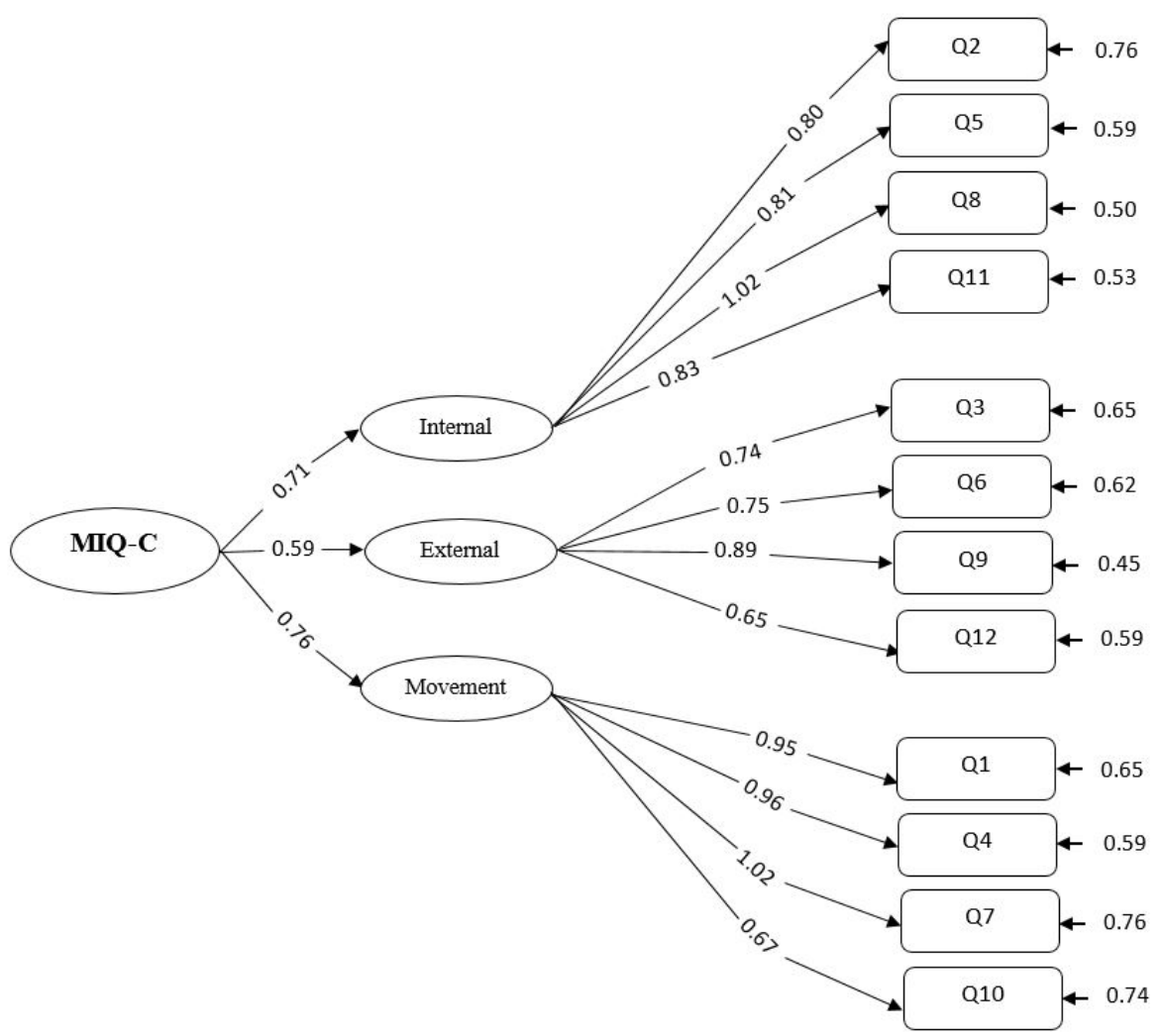

Fig 2. Standardized estimate of 3 factor and 12 questions model of MIQ-C.

The purpose of this study was to investigate the functional structure of the pediatric MIQ-C. If the results of this study showed that the three-factor model was suitable for this questionnaire. This three-factor model was introduced based on previous studies (Martini \& et al., 2016; Hojati, 2013; Hall \& et al., 1997) as well as exploratory factor analysis (Table.1 and Figure.1). Indices obtained in this model were compared in comparison with the values obtained from these indices in earlier studies. Martini and et al., (2016), 
in a study of 204 healthy children ages 7 to 12 , also developed a three-factor model with 12 items, indicating that the values of goodness fit indicators reported for it fit well $(\chi 2 / \mathrm{df}=1.09, \mathrm{CFI}=0.93$, GFI $=0.95, \mathrm{RMSEA}=0.07, \mathrm{SRMR}=0.05, \mathrm{TLI}=0.89$ ) In another study, conducted by Hojati (2013) in his research on 319 adults, he reported a three-factor model that measures the obtained indices similar to those of the previous study $(\chi 2 / \mathrm{df}=2.67, \mathrm{CFI}=$ 0.98, GFI $=0.96$, RMSEA $=0.07$ ). Among the features of the current research, the exploratory factor analysis is performed before the confirmatory factor analysis. In a comparison between the results of the exploratory and confirmatory analysis, it is also seen that all of the content of this questionnaire can be limited to three general factors, which are, in fact, subscales of the test. At first, exploratory factor analysis showed us that each of the items is more appropriate for which factor, and a confirmatory factor analysis also showed that a three-factor model with 12 items has been approved.

\section{Conclusions}

The results of this study are not so different from those of previous ones, and in general they can be said to be in line with previous results. Finally the results showed that the Persian version of the MIQ-C is recommended to measure the ability to Imagery children from 7 to 12 years of old in the Persian language. According to the researchers, one of the reasons influencing this tool in the Iranian society is the lack of cultural factors involved in the present questionnaire.

\section{Note}

The information contained in this article was extracted from the M.A. thesis of the author, Meysam Yavari Kateb, submitted in Sport Psychology at University of Tehran, Tehran, Iran.

\section{References}

1. Azadi, Y., Ghaemi, B. (2014). Applied Sport Psychology, Avaye zohoor, 1th. Ed. 2014; PP: 8-23 [Persian].

2. Bartlet, M. S. (1950)." The stiff significance in factor analysis". British Journal of Psychology, (3). PP: 77-85.

3. Caeyenberghs, K., Tsoupas, J., Wilson, P. H., \& Smits-Engels man, B. C. M. (2009). Motor imagery in primary school children. Developmental Neuropsychology, 34(1), PP: 103-121.

4. Callow, N., \& Waters, A. (2005). The effect of kinesthetic imagery on the sport confidence of flatrace jockeys. Psychology of Sport and Exercise, 6, PP: 443-459.

5. Costello, A. B., \& Osborne, J. W. (2005). Best practices in exploratory factor analysis: Four recommendations for getting the most from your analysis. Practical assessment, research \& evaluation, 10(7), PP: 1-9.

6. Cumming, J., \& Williams, S. E. (2012). The role of imagery in performance. In S. Murphy (Ed.), Handbook of sport and performance psychology (PP. 213-232). New York, NY: Oxford University Press.

7. Cumming, J., \& Williams, S. E. (2013). Advice for Developing Effective Imagery for Athletes for Children (MIQ-C). Psychology of Sport and Exercise, 22, (2016), PP: 190-201.

8. Gabbard, C. (2009). Studying action representation in children via motor imagery. Brain and Cognition, 71, PP: 234-239.

9. Gabbard, C., \& Bobbio, T. (2011). The inability to mentally represent action may be associated with performance deficits in children with developmental coordination disorder. International Journal of Neuroscience, 121, PP: 113-212.

10. Gabbard, C., Caçola, P., \& Bobbio, T. (2011). The ability to mentally represent action is associated with low motor ability in children: a preliminary investigation. Child: Care, Health and Development, 38, PP: 390-393. 
11. Giles, D. C. (2002). Advanced research methods in psychology, Rout ledge, P. 87.

12. Guillot, A., \& Collet, C. (2008). Construction of the motor imagery integrative model in sport: a review and theoretical investigation of motor imagery use. International Review of Sport and Exercise Psychology, 1(1), 31-44.

13. Halavari, H., \& Thomassen, T. O. (1997)."Achievement sport related future orientation and sporting career" Genetic, social and general psychology monographs, 123(3), PP: 343 350.

14. Hall, C. R., \& Martin, K. A. (1997). Measuring movement imagery abilities: a revision of the movement imagery Questionnaire. Journal of Mental Imagery, 21, PP: 143-154.

15. Hemayat talab, R., Shykh, M., Movahedi, A., Assad, M.R. (2008). The Effect of primacy and regency the mental training on the Learning of PerceptualMotion Skill with Emphasis on Internal and External Imaging, Research Journal of Sport Sciences, No. 14, PP: 131-155.

16. Heremans, E., Helsen, W. F., \& Feys, P. (2008). The eyes as a mirror of our thoughts: quantification of motor imagery through eye movement registration. Behavioral Brain Research, 187, PP: 351-360.

17. Hojati, A. (2013). [Psychometric Properties of Persian Version of the Movement Imagery Questionnaire-3, Thesis for M.Sc. Degree in Sport Psychology, University of Tehran, Faculty of Sport Science.

18. Hu, L., \& Bentler, P.M. (1999). "Cutoff criteria for fi $\mathrm{t}$ indexes in covariance structure analysis: Conventional criteria versus new alternatives". Structural Equation Modeling: A Multidisciplinary Journal, 6. PP: 1-55.

19. Isaac, A. R., \& Marks, D. F. (1994). Individual differences in mental imagery experience: developmental changes and specialization. British Journal of Psychology, 85, PP: 479-500.

20. Jackson, Ph. L., Lafleur, M. F., Malouin, F., Richards C., \& Doyon, J. (2001). Potential role of mental practice using motor imagery in neurologic rehabilitation, Archives of Physical Medicine and Rehabilitation, Volume 82, Issue 8, August 2001, PP: 1133-1141.

21. Jeannerod, M. (1995). Mental imagery in the motor context. Neuropsychological, 33(I1), PP: 1419 1432.

22. Jorekog, K.G, Sorbom, D. (1996). Lisrel 8: Users, Reference Guide, Scientific Software International, Inc.Chicago.
23. Kline, P. (2013). "Principles and practice of structural equation modelling". 4nd New York: The Guildford Press. PP: 9-64.

24. Knackstedt, P. (2011). Optimal timing of a PETTLEP mental imagery intervention on a dart throwing task. The University of North Carolina at Greensboro.

25. Mantani, T., Okamoto, Y., Shirao, N., Okada, G., \& Yamawaki, S. (2005). Reduced activation of posterior cingulate cortex during imagery in subjects with high degrees of alexithymia: a functional magnetic resonance imaging study. Biological Psychiatry, 57(9), 982-990.

26. Marcel, J., \& Paquet, Y. (2005). "French validation of the modified version of the SAS." L'Encephale, 36(2). PP: 16-121.

27. Martini, R., Carter, M. Yoxon, E., Cumming, J., \& Ste-Marie, D. (2016). Development and validation of the Movement Imagery Questionnaire for Children (MIQ- C). Psychology of Sport and Exercise, 22, PP: 190-201.

28. Mattie, P., \& Munroe-Chandler, K. (2012). Examining the relationship between mental toughness and imagery use. Journal of Applied Sport Psychology, 24(2), PP: 144-156.

29. McAvinue, L. P., \& Robertson, I. H. (2008). Measuring motor imagery ability: a review. European Journal of Cognitive Psychology, 20(2), PP: 232-251.

30. McAvinue, L. P., \& Robertson, I. H. (2009). An evaluation of a movement imagery training scheme. Imagination, Cognition, and Personality, 29, PP: 99114.

31. Molina, M., Tijus, C., \& Jouen, F. (2008). The emergence of motor imagery in children. Journal of Experimental Child Psychology, 99, PP: 196-209.

32. Richardson, A. (1967). Mental practice: a review and discussion (part 11). Journal of Research Quarterly, 38, PP: 263-273.

33. Saab, S., Bastek, J., Dayaratna, S., Hutton, E., \& Catherine, R. (2017). Development and Validation of a Mental Practice Tool for Total Abdominal Hysterectomy. Journal of Surgical Education, Volume 74, Issue 2, March-April 2017, PP: 216221.

34. Schuster, C., Glässel, A., Scheidhauer, A., Ettlin, T., \& Butler, J. (2012). Motor imagery experiences and use: asking patients after stroke where, when, what, why, and how they use imagery: a qualitative investigation. Stroke research and treatment, 2012.

35. Skoura, X., Vinter, A., \& Papaxanthis, C. (2005). Mentally simulated motor actions in children. Developmental Neuropsychology, 34, 356-367. 
36. Smith, D., Wright, C., \& Cantwell, C. (2008). "Beating the bunker: The effect of PETTLEP imagery on golf bunker shot performance". Research Quarterly for Exercise and Sport, 79(3), PP: 385-391.

37. Spruijt, S., van der Kamp, J., \& Steenbergen, B. (2015). Current insights in the development of children's motor imagery ability. Frontiers in psychology, 6, 787.

38. Stadulis, R. E., MacCracken, M. J., Eidson, T. A., \& Severance, C. (2002). The competitive state anxiety inventory for children-the CSAI-2C. Measurement in Physical Education and Exercise Science, 6, PP: 147-165.

39. Taktek, K., Zinsser, N., \& St John, B. (2008). Visual versus kinesthetic mental imagery: efficacy for the retention and transfer of a closed motor skill in young children. Journal of Experimental Psychology, 62(3), PP: 174-187.

40. Vealey, R. S., \& Greenleaf, C. A. (2001). Seeing believes: understanding and using imagery in sport. In J. M. Williams (Ed.), applied sport psychology: Personal growth to peak performance (PP: 247-283). Mountain View, CA: Mayfield Publishing Company.

41. Veraksa, A., \& Gorovaya, A. (2012). Imagery training efficacy among novice soccer players. Procedia-Social and Behavioral Sciences, 33, 338342.

42. Wakefield, C. J., \& Smith, D. (2009). Impact of differing frequencies of PETTLEP imagery on netball shooting performance. Journal of imagery research in sport and physical activity, 4(1).

43. Weinberg, R. S., Gould, D. (2011). Foundations of Sport and Exercise Psychology, 5th Ed, 2011; PP: 11-42.

44. White, A., \& Hardy, L. (1995). Use of different imagery perspectives on the learning and performance of different motor skills. British Journal of Psychology, 86, PP: 169-180.

45. Williams, S. E., Cumming, J., Ntoumanis, N., Nordin-Bates, S. M., Ramsey, R., \& Hall, C. (2012). Further validation and development of the movement imagery questionnaire. Journal of Sport \& Exercise Psychology, 34, PP: 621-646. 